Recebido: $11 / 10 / 2018$

Aprovado: 14/12/2018

\title{
A aproximação luso-brasileira nos tempos do Estado Novo e a Revista Atlântico (1942-1945)
}

Guilherme Nercolini Miranda ${ }^{1}$

Resumo: O contexto do Brasil durante a Segunda Guerra Mundial é comumente conhecido pela forte aproximação do país com os Estados Unidos da América. Entretanto, foi durante os anos do conflito global que Portugal e Brasil se aproximaram de maneira acintosa. Desta aproximação resultou o Acordo Cultural Luso-Brasileiro de 1941 e uma de suas consequências: a Atlântico: Revista LusoBrasileira. No presente artigo busco, através das páginas deste periódico, perceber como os discursos que permeavam as relações luso-brasileiras foram trabalhados pelos intelectuais dos dois países. Através disto procuro perceber quais as motivações orientaram as relações luso-brasileiras e quais resultados foram obtidos a respeito dessas ações. Para isto utilizo o método da análise de periódico de Tânia Regina de Luca como ferramenta para perceber na própria revista Atlântico os discursos e intensões que permearam as relações lusobrasileiras dos anos de 1942 a 1945.

\footnotetext{
${ }^{1}$ Doutorando pela Universidade Federal do Paraná, atualmente é orientado pelo prof. Dr. Dennison de Oliveira e bolsista CAPES. E-mail: guilhermemiranda89@gmail.com
} 
Palavras-chaves: Revista Atlântico; Estado Novo; Relações Luso-Brasileiras.

Abstract: The context of Brazil during World War II is commonly known by the strong approximation of the country with the United States of America. However, it was during the years of global conflict that Portugal and Brazil approached in an acerbic manner. This approach resulted in the 1941 Luso-Brazilian Cultural Agreement and one of its consequences: the Atlântico: Revista Luso-Brasileira. In this article, I search through the pages of this journal to understand how the discourses that permeated Portuguese-Brazilian relations were worked by the intellectuals of the two countries. Through this, I try to understand what motivations have guided Portuguese-Brazilian relations and what results have been obtained regarding these actions. For this, I use the method of periodic analysis of Tânia Regina de Luca as a tool to perceive in the Atlantic magazine itself the discourses and intentions that permeated Portuguese-Brazilian relations from the years 1942 to 1945.

Keywords: Revista Atlântico; Estado Novo; Luso-Brazilian Relations.

\section{Introdução}

As páginas da Atlântico: Revista Luso-Brasileira são marcas de um período de consolidação de uma política voltada pela aproximação luso-brasileira. Caracterizados pelas rápidas mudanças ocorridas nos anos entre a Grande Guerra e a Segunda Guerra Mundial, e também pelas quebras governamentais dos sistemas políticos vigentes nos dois países, tanto Portugal quanto o Brasil tiveram nos anos de 1937 a 1945 uma semelhança em comum: ambos foram governados por sistemas políticos de cunho autoritário denominados Estado Novo.

As semelhanças das características políticas dos dois países são advindas desde períodos anteriores. Os vínculos afetivos ou ideológicos entre a classe política lusobrasileira invariavelmente conectaram as elites intelectuais dos dois países desde a segunda metade do século XIX. Ainda que os sentimentos anti-lusitano fosse evidente em parte da sociedade brasileira do pós-independência (CERVO; MAGALHÃES, 2000, p.256-257), há de notar-se que o movimento republicano no Brasil teve importante influência nos eventos que sucederam a queda da monarquia portuguesa e consequente implementação da República em Portugal no ano de 1910 (GOLÇALVES, 2014, p.6869)

\section{Filstontorias}


Os eventos políticos posteriores também refletem a proximidade dos dois países. Tanto Portugal quanto o Brasil tiveram golpes de Estado revolucionários durante a década de 1920. Ambos também presenciaram governos ditatoriais durante as décadas de 1930 e 1940, sendo o período dos Estados-Novos uma confluência de ideias e de práticas que somados eram símbolo de um período de consolidação de modelos políticos inspirados no fascismo italiano, e que também afirmavam a negação ao modelo democrático-liberal anglo-saxão e comunista.

Os dois governos tinham, com isso, muitas particularidades em comum. Neste sentido, no entanto, seria possível pensar através das semelhanças dos dois regimes uma possível cumplicidade luso-brasileira, seja de forma oficial ou extraoficial, que servisse para a legitimação dos dois governos estado-novistas?

Esta é uma questão fundamental que perpassa por pensar não somente no que os dois governos se assemelham, mas também quais as suas diferenças. Nas similaridades diversas questões despontam, cada uma com sua característica.

Em primeiro lugar, e este é um ponto de partida essencial, é preciso visualizar que as temporalidades dos dois regimes os aproximavam. Ainda que seja clara a diferença de extensão dos dois, tendo o Estado Novo português durado de 1933 a 1974, ou seja, um longo período de tempo comparado ao brasileiro que teve a longevidade de 1937 até 1945, é percebível que os dois países tiveram na década de 1930 e no período antecedente e durante à Segunda Guerra Mundial tanto o início quanto a consolidação de seus regimes. Este é um dado importante, pois, para além de possíveis diferenças, os dois EstadosNovos formaram suas instituições administrativas durante o mesmo período.

O segundo ponto destacável a respeito dos dois regimes é relacionado a matriz de suas vertentes políticas. Tanto no Estado Novo lusitano quanto brasileiro destacaram a participação de parcelas conservadoras da sociedade dos dois países na implantação das respectivas ditaduras (PINTO In. MARTINHO; PINTO, 2007, p.40). Embora similares neste sentido, há a partir daí uma diferença entre os dois regimes.

No caso do Estado Novo português, as bases do regime político de Oliveira Salazar são formuladas através da união de três grupos sociais distintos: o partido da União Nacional, a Igreja Católica e as alas conservadoras das Forças Armadas 
Portuguesas. Neste sentido, o papel da Igreja Católica tinha grande destaque na figura do Cardeal Manuel Gonçalves Cerejeira tanto na constituição de importantes instituições sociais e políticas, como a Acção Católica Portuguesa em 1933 e na expansão das ideias católicas e anticomunistas pelo país.

No lado brasileiro as diferenças mais acintosas em relação ao Estado Novo português eram: o posicionamento agnóstico de Getúlio Vargas a respeito da participação da Igreja no regime e a importância do Integralismo na formação dos organismos do Estado Novo brasileiro. No caso da Igreja, ainda que Vargas tenha estreitado laços com a instituição em busca de apoio massivo no âmbito da propaganda em troca da permissão do ensino do catolicismo nas escolas públicas, nunca houvera uma institucionalização da Igreja no interior do aparelho de Estado no Brasil de Vargas como aconteceu no caso português ${ }^{2}$.

O Integralismo, por outro lado, acabou por destacar-se no cenário brasileiro. Embora ele tenha nascido de maneira similar tanto em Portugal quanto no Brasil, e estivessem de acordo com matrizes ideológicas e políticas em comum, o integralismo no país luso nunca assumiu formas de partido político e nem teve importância dentro do cenário político português. Nos anos 1930 no Brasil, por outro lado, a Ação Integralista Brasileira (AIB) comandada por Plínio Salgado desempenhou um importante papel na política do período, que acarretou em uma conflituosa relação com o governo de Vargas e interferiu diretamente nas políticas do regime varguista.

Embora, como demonstrado acima, os dois casos se diferenciem por conta de seus contextos internos distintos, o Varguismo e o Salazarismo tinham quatro características que os faziam bastante parecidos: o autoritarismo como forma de gestão de governo, o corporativismo como regulador da crise social que atingia os dois países, o viés anticomunista e a aversão aos modelos democrático-liberais das potências anglo-saxãs.

\footnotetext{
${ }^{2}$ Apesar da aproximação do regime varguista em relação a Igreja Católica, efetivada principalmente com o sepultamento do laicismo e restituição do ensino religioso nas escolas brasileiras, a sua participação no regime de Getúlio Vargas foi pouco consolidada comparado ao caso Português onde a instituição religiosa efetivamente esteve presente no aparelho do Estado. Estre as ações em que coordenou, a Igreja Católica sob liderança do Cardeal Manuel Gonçalves Cerejeira esteve presente em algumas das principais instituições do regime como a Acção Católica Portuguesa (ACP) e na promoção da "recristianização" de Portugal onde teve amplo espaço de ação com o fim de dissolver as ideias republicanas e liberais de dentro de Portugal.
} 
Neste sentido os dois regimes tinham como característica primordial a ênfase ao autoritarismo de cunho fascista ligados às principais instituições matrizes de seus governos: no caso português à União Nacional e a Igreja; no brasileiro direcionado em prol da unidade nacional e da expansão do desenvolvimento do Capital Industrial, com o fortalecimento da personificação de Getúlio Vargas para a formação de uma centralização política em prol do enfraquecimento das elites regionais.

Por fim, mas não menos importante, a participação dos intelectuais na consolidação e legitimação dos dois regimes políticos foi um mecanismo fundamental. Conforme Pécaut (1990) e Gomes (2007) expuseram, as elites letradas brasileiras dos anos 1920 a 1940 tiveram como característica a associação com o regime cujas metas eram a criação de uma nacionalidade e aproximação dos grupos dirigentes afim de legitimarem seus próprios espaços como elite. Neste sentido, através do uso do "poder intelectual”, ou seja, com a posse da compreensão do saber da organização social, eles se utilizaram dos estudos sociais e linguísticos como forma de legitimação tanto de suas posições sociais quanto dos espaços estatais e instituições públicas das quais frequentavam.

Neste sentido, através do corporativismo dos regimes estado-novistas lusobrasileiro, os governos de Salazar e Vargas procuraram seduzir as elites letradas para se utilizarem destes grupos com o propósito de absorve-los no trabalho de legitimação das ideias e das instituições de ambos os regimes. Com isso, podemos perceber nos exemplos de Francisco Campos e António Ferro, que assumiram espaços importantes dos governos dos dois países, esta ação de associação da elite letrada para o fortalecimento das bases institucionais e é neste ponto que o periódico Atlântico: Revista Luso-Brasileira está associado (PECAUT, 1990, p.25-34).

\section{Por uma Política do Atlântico}

Entre as semelhanças encontradas entre os governos de Oliveira Salazar e Getúlio Vargas, e que aproximou os dois países durante os anos 1930 e 1940, perpassavam pelo empenho dos dois governos em posicionar-se de forma autônoma perante o cenário internacional de guerra.

\section{Filstóntorias}


Ainda que na área econômica não tenha existido comum acordo entre os dois países, muito ocasionada pela interferência da projeção pan-americanista pelo Brasil e pelo extensivo comércio de Portugal com suas colônias africanas e asiáticas, as necessidades da manutenção dos dois regimes em meio aos processos da guerra obrigavam ambos a constituírem uma consciencialização recíproca afim de fortalecer as próprias instituições internas (SANTOS, 2010, p.8-9).

Esta estratégia era proveitosa para o governo de Getúlio Vargas por uma série de questões: Primeiramente, era manifesto o alinhamento ideológico do presidente brasileiro com os regimes autoritários europeus. Com o estabelecimento do Estado Novo, em 1937, e o fortalecimento do poder autoritário do governo brasileiro, Vargas necessitava de mecanismos de legitimação para sua manutenção no poder, algo que ele encontrava ao aproximar-se de outros governos similares, como o Português.

Em segundo, é preciso lembrar que este é um período de construção da identidade nacional brasileira ${ }^{3}$, e para além de sua legitimação interna em um período de incertezas, por conta do grande número de estrangeiros vivendo em terras brasileiras, era também necessário expandir esta identidade para o exterior afim de projetar o Brasil como um Estado unificado.

A vitrine portuguesa na Europa possibilitava ao Brasil não apenas a oportunidade de propagandear sua soberania como país em franca expansão econômica no continente americano, como também ajudava no fortalecimento da identidade nacional brasileira, que ainda sofria da mescla cultural ocorrida poucas décadas antes pela grande imigração europeia para o país. Também é preciso salientar que a aproximação brasileira com Portugal ampliava os argumentos do Brasil como "filho" da Europa, diminuindo, com isso, a importância das influências indígenas e africanas na sociedade e cultura local.

Por fim, a ideia de uma aliança luso-brasileira era proveitosa para o regime varguista, pois, reintroduzia o discurso de um domínio do Atlântico Sul pelos povos de língua portuguesa. Este sonho, que fora uma aspiração originária desde os tempos do império português no século XVIII, indicava um possível domínio triangular na região encabeçado pelo Rio de Janeiro, Lisboa e Luanda.

\footnotetext{
${ }^{3}$ Conforme apontado por Antônio C. S. Almeida (2011, p.165), as décadas de 1930 e 1940 são marcadas pela elaboração teórica da construção da identidade nacional brasileira, com especial destaque a intelectuais como Gilberto Freyre com seu livro Casa Grande \& Senzala (1933), Sérgio Buarque de Hollanda com Raízes do Brasil (1937) e Caio Prado Júnior com Formação do Brasil Contemporâneo (1945).
} 
É perceptível, portanto, que apesar do campo econômico não ter sido ampliado, o ponto fulcral da aliança luso-brasileira nos anos 1930 e 1940 era focado principalmente no campo da cultura. Neste sentido, a data de 4 de setembro de 1941 marcou a assinatura de uma tentativa de aproximação literária, cultural e principalmente ideológica, que foi denominado Acôrdo Cultural Luso-Brasileiro.

A importância do acordo cultural de 1941 perpassava na construção de mecanismos de perpetuação e legitimação de poder. Conforme SANTOS afirma acerca da utilização da propaganda em Portugal, a:

(...) disseminação por vários meios de comunicação, a propaganda imperial tinha como objetivo principal envolver a população, de tal modo que se sentisse participante ativa do governo (...) Houve um bombardeio de campanhas que muitas vezes funcionavam como uma lavagem cerebral, exacerbando um nacionalismo baseado em referência aos feitos históricos do passado português (SANTOS, 2009, p.46-47)

A exemplo da prática exercida pelo governo de Lisboa, o Estado Novo brasileiro também propôs, de forma análoga, "recortar" da história personagens, datas ou eventos que dessem forma a uma versão oficial da História do país (SILVA, 2011, p.103).

Neste sentido, portanto, tanto o governo português quanto o brasileiro propuseram construir conexões através do Acôrdo Cultural Luso-Brasileiro com o afinco de criar estes mecanismos. Assim, para o regime varguista, esta era uma oportunidade de fortalecer o governo através da consciencialização recíproca, com o propósito de posicionar tanto o país quanto o Estado-Novo em um espaço de destaque no cenário interno e externo.

O documento fora assinado por António Ferro ${ }^{4}$, então diretor do Secretariado de Propaganda Nacional (SPN) e Lourival Fontes ${ }^{5}$ que dirigia o Departamento de Imprensa e Propaganda (DIP) em 1941, e tinha como meta uma série de ações de cunho artístico, diplomático e cultural, sendo dividido em três artigos.

\footnotetext{
${ }^{4}$ António Ferro (1895-1956) foi um intelectual e político português da primeira metade do século XX. Escritor e jornalista, teve influente carreira em diversos jornais de Portugal, tendo sido chamado por Oliveira Salazar para dirigir o Secretariado da Propaganda Nacional (SPN), cargo que atuou de 1933 a 1949. Ferro teve importante papel na propaganda do Estado Novo português, tendo sido responsável pela criação de diversas obras de propaganda nacional, como a Exposição do Mundo Português (1940), a Revista dos Centenários (1939), fundou o Museu de Arte Popular (1940) e foi presidente da Emissora Nacional (1941).

${ }^{5}$ Lourival Fontes foi diretor da DIP durante os anos de 1939 a 1942, tendo sido sucedido pelo Major Coelho do Reis de agosto de 1942 até julho de 1943 e pelo capitão Amilcar Dutra de Menezes que dirigiu o órgão até a sua extinção em maio de 1945.
} 
O primeiro dava conta da criação de uma sessão portuguesa na DIP e uma brasileira na SPN. Essas sessões, segundo afirma o acordo, tinham a incumbência de "assegurar e promover, pelos meios ao seu alcance, tudo o que possa concorrer para tornar conhecida, respectivamente, no Brasil e em Portugal, a cultura dos dois países” (SECRETARIADO DE PROPAGANDA NACIONAL, 1941).

O segundo artigo do acordo previa uma série de ações como: a publicação de uma revista cujo nome especificara-se como Atlântico; a troca de colaborações culturais e acadêmicas com o envio de palestrantes e artistas; a publicação e divulgação de livros, artigos e fotografias brasileiras e portuguesas nos dois países; emissões de rádios conjuntas; criação de um prêmio literário; troca de atualidades cinematográficas e colaboração recíproca em favor de uma orientação comum em todos os noticiários de divulgação que expressassem opiniões acerca de Portugal e do Brasil.

Por fim, o terceiro artigo apontava a data de 31 de dezembro de 1941 para a entrada em vigor do Acordo Cultural. O documento previa, portanto, para além da colaboração cultural, uma cooperação em relação às orientações comuns dos Estados Novos $^{6}$. Apesar da imensidão de orientações citadas pelo acordo, um dos destaques presentes neste é a própria criação da revista Atlântico, quando no Artigo $2^{\circ}$ cita-se que:

Para efeitos do artigo anterior, as duas secções criadas por êste acôrdo promoverão especialmente: (...) a criação duma revista denominada Atlântico, mantida pelos dois organismos, com a colaboração de escritores e jornalistas portugueses e brasileiros. (SECRETARIADO DE PROPAGANDA NACIONAL, 1941)

A revista Atlântico fazia parte do cerne deste acordo cuja intencionalidade perpassava pela edificação da identidade luso-brasileira e de uma cultura política pautada na tradição lusa e nos fundamentos do catolicismo, como nos moldes da "política do espírito" formulada por António Ferro ${ }^{7}$.

\footnotetext{
${ }^{6}$ Dentre as criações construídas através deste acordo de cooperação, destacava-se também a revista Brasília, publicada pelo Instituto de Estudos Brasileiros da Universidade de Coimbra. Com apoio do SPN, a revista tinha cunho acadêmico e focava-se nos segmentos das línguas, literaturas e história do Brasil. Para Élio Serpa (2010), a revista tinha como propósito enfatizar que ambos os países não possuíam ideias divergente e de que, ao final, o Brasil era fiel a sua formação histórica.

${ }^{7}$ António Ferro descrevia a "Política de Espírito" como uma "matéria prima da alma dos homens e da alma dos povos", mas também via nesta uma oposição a política da matéria e a "tudo o que suja o espírito, fazendo o necessário para evitar certas pinturas viciosas do vício que prejudicam a beleza, como certos crimes e taras ofendem a humanidade, a felicidade do homem. Defender a Política de Espírito é combater sistematicamente, obra da vida e obra da arte, tudo o que é feio, grosseiro, bestial, tudo o que é maléfico, doentio por simples volúpia ou satanismo". (TORGAL,1999, p.405).
} 
A Política de Espírito defendida por António Ferro tinha em sua premissa ser uma forma de contraponto de um modelo latino ao modo de pensar ideológico e político anglosaxão, pautado no modelo do liberalismo e da democracia. Ferro apontava que era necessário confrontar o "Espírito" contra a "Matéria", sendo que ele assinalava a existência de um binarismo entre o "Espírito do Bem", que seria propriamente o espírito exemplificado pelo "belo", pelas artes e pela moralidade espiritual cristã e o "Espírito do Mal", que é representado pelo satanismo e pelo materialismo. Conforme Graça dos Santos apontou:

Esta visão binária (espírito versus matéria, Mal versus Bem) subentende a orientação estética que será desenhada pela propaganda salazarista, e consequentemente ao apresentado na revista Atlântico. Associa-se o bem ao espírito (alma, sonho, céu...) e o mal à matéria (quotidiano, real, terra...); definem-se os artistas correspondendo a estes ditames como "criadores de beleza" devendo estes procurar as alturas e não o chão (SANTOS, 2008, p.62).

Foi com binarismo e com ênfase nas “elevações latinas”, vista como aproximação da religiosidade e das artes em relação aos sentidos mundanos e ao concreto (e neste sentido podem ser incluídos os estudos da economia, da política e do quotidiano) que a Atlântico foi pensada e concebida. Foram, portanto, com estas premissas permanentemente focadas na “espiritualidade” que a revista foi construída.

Por este motivo este viés originário da Política de Espírito circulou em diversos escritos na Atlântico. Um exemplo deste discurso é visto, por exemplo, na fala de Genolino Amado, onde em seu texto intitulado O prestígio dos vulgarizadores publicado na sexta edição da Atlântico ele aponta que:

O homem do século XX vive acorrentado a um optimismo pragmatista que tende sempre, até no plano da cultura, para a formação gozadora e interesseira de unir o útil ao agradável. A intenção de lucro positivo e imediato compromete mesmo os seus mais inocentes prazeres (...) porque não admite mais a entrega do seu próprio ser a uma expressão da vida que não tenha vantagem certa, que não represente uma aquisição ou uma defesa. (AMADO In. ATLÂNTICO, n 6, 1945, p.175)

Ou seja, para ele o "homem moderno” estaria mais interessado nas materialidades de suas ações, seja através do lucro ou do recebimento de algo em troca de suas ações do que pelo prazer simples, pela própria “espiritualidade” de suas ações.

Foi através da propagação deste tipo de pensamento e por conta do Acôrdo Cultural Luso-Brasileiro de 1941 que a Atlântico passou a circular por entre as principais cidades portuguesas e brasileiras a partir de maio de 1942. Para os brasileiros era uma possibilidade de expandir suas obras, oferecendo para os espaços europeus a produção 
intelectual do país. Para a intelectualidade portuguesa era oportuno este intercâmbio com alguns dos artistas modernistas mais influente do mundo lusófono.

O acordo foi, por isso, uma oportunidade para os dois povos expandirem suas obras culturais, como espaço de propaganda para os governos. O periódico também foi uma possibilidade de fortalecer temas centrais para os regimes Estado Novistas. A Atlântico tinha, portanto, um papel fundamental dentro deste acordo, e por isso a produção da revista espelha o esmero de seus produtores para engrandecer sua existência.

A Atlântico em suas seis primeiras edições ${ }^{8}$ tinha como características principais a alta qualidade em sua produção, o que demonstrava o cuidado em desponta-la como espaço de sociabilidade artística e ideológica. Para isto foi contratado o artista gráfico e decorador português Manuel Lapa, conhecido por sua filiação ao movimento modernista de Portugal e amizade com António Ferro.

Além de Lapa, outro importante nome contratado para a materialização da revista foi José Osório de Oliveira. Ele, que fora um influente ficcionista, poeta e crítico literário, foi incumbido na função de secretário da redação da Atlântico, espaço que ocupou em todas as seis edições do periódico.

A escolha pelo nome de Oliveira em tão importante função dentro da Atlântico ocorreu não somente pelo fato dele ter circulado diversas vezes por Cabo Verde, Brasil e África Ocidental como também porque ele possuía uma vasta rede de contatos nestas regiões. Dentre nomes ilustres conhecidos por Oliveira pode-se citar Mário de Andrade, Sérgio Buarque de Holanda, Gilberto Freyre, Plínio Salgado, Rui Ribeira Couto e Cecilia Meireles (SOUZA, 2015, p.102).

Através do trabalho artístico de Lapa e considerações de José Osório de Oliveira o periódico destacava-se por seu rico detalhamento e construção, sendo cada edição da revista uma obra de cuidado e capricho. Na parte gráfica, cada número destacava uma coloração representativa própria. Além disso, as letras e espaços eram ornamentados com diversas obras produzidas por artistas luso-brasileiros, principalmente de Manuel Lapa.

\footnotetext{
${ }^{8}$ O periódico Atlântico: Revista Luso-Brasileira teve durante sua existência um total de treze edições, tendo a numeração de um até a seis durante os anos de 1942 a 1945, período em que foi patrocinada pela DIP e pelo SPN. A partir do ano de 1946 o periódico deixou de receber investimentos do lado brasileiro, tendo sobrevivido de 1946 até 1949 com investimentos exclusivos do Secretariado Nacional de Informação de Portugal, período que recebeu uma nova série de numeração contando sete edições de 1946 a 1949.
} 
A letra também possuía tamanho mediano, sem economia de páginas, e o material da revista era de papel com folhas espessas e firmes.

Um outro ponto acerca da materialidade da revista refere-se a constante reprodução de imagens sugestivos ao oceano Atlântico e a Cristandade, símbolos do que os diretores da revista apontavam como ícones de união dos povos lusófonos. Neste sentido, a revista tem enfoque nestes dois temas já que estes são símbolos predominantes da imagem ao qual seus idealizadores sugerem como a “raça lusitana”, como exposto por Lourival Fontes em sua fala a respeito da ideia de uma Unidade Espiritual entre os povos lusófonos. Fontes, neste sentido, aponta que "portugueses e brasileiros são admitidos em comum, sob influxos de sentimentos duma cordialidade imperturbável. Tudo colabora nessa harmonia. O idioma a religião, as preferências, as fontes de orgulho patriótico ” (FONTES In. ATLÂNTICO, nº1, 1942, p.1).

Através da materialidade da Atlântico podemos perceber, portanto, que sua produção se encaixava não somente na ideia de um espaço de sociabilidades entre intelectuais luso-brasileiros, mas também de fazê-la como uma espécie de antologia da “raça lusitana”, como um ambiente não apenas de diálogo, mas também de construção de identidade e legitimidades.

Ainda a respeito da Atlântico e sua forma é preciso salientar que ela tinha uma materialidade bastante imponente, com o tamanho e a forma de cada edição fluindo de 170 a 200 páginas. Seu formato era semelhante ao de um livro para cada edição, divididas em cinco partes: No início de cada edição da revista era exposto os principais artigos e fragmentos de estudo selecionados pelo editorial, geralmente envolto em assuntos referentes aos assuntos culturais e políticos, por vezes selecionados sobre alguns temas específicos.

Em seguida a revista direciona os leitores à apreciação de poemas diversos enquanto em um terceiro momento o leitor poderia ler textos literários de escritores brasileiros e portugueses, nos quais os editores apresentavam uma quantidade de cinco a dez textos literários por edição.

No quarto espaço da Atlântico há um retorno aos artigos e fragmentos de estudo. A temática deste espaço é mais voltada as exposições musicais, cinematográficas ou teatrais nas cidades do Rio de Janeiro e Lisboa. Há também uma vertente crítica neste bloco que direcionam seus destaques nas análises de livros, autores ou problemas estruturais dos espaços culturais luso-brasileiros, como visto nos artigos Possibilidades 
do Cinema Português de Fernando Garcia presente na primeira edição da revista e $O$ preconceito “Intelectual” Contra o Teatro Português por António Lopes Ribeiro localizado na terceira edição da Atlântico.

Por fim, cada edição da Atlântico apresenta um espaço onde o redator expunha as notas referentes aquela edição, com erratas da edição anterior, dificuldades na publicação e tiragem de dúvidas ou apontamentos referentes ao prosseguimento do periódico

Por ter este viés de espaço de diálogo e de ser concebida como uma "antologia à civilização lusitana” a revista não apenas era isenta de patrocínios como também seu alcance e inserção dentro das sociedades brasileira e portuguesa atraiu diversos intelectuais tanto a favor quanto contrários aos regimes salazarista e varguista, como percebido através da participação de nomes como Aquilino Ribeiro, Sofia de Mello Breyner Andresen, Jorge de Sena, Jorge Amado, Caio Prado Jr. e Carlos Drummond de Andrade nos escritos da revista.

O próprio José Osório de Oliveira, em nota da redação da segunda edição da revista, apontou que "o êxito que a Atlântico alcançou no Brasil convence-nos de que seguimos o bom caminho da Aproximação” (OLIVEIRA In. ATLÂNTICO, n²2, 1942, p.367). Ainda que não haja dados numéricos a respeito da receptividade do periódico, esta receptividade por variados intelectuais de ambos os países nos fazem perceber que a Atlântico atingiu certo grau de resultados positivos como espaço diálogo cultural e artístico.

Através destas informações podemos perceber, portanto, que a Atlântico tinha acima de tudo, um propósito. Sua publicação com suporte binacional e influência tanto da DIP quanto da SPN, o cruzamento de temas e a ênfase em possibilitar a participação tanto de brasileiros quanto de portugueses demonstram que, como José Osório de Oliveira apontou em notas da primeira edição, “esta revista não surge por acaso, mas por determinação do Acôrdo Cultural. Por isso, tem uma razão de ser, um objetivo, um critério, uma feição especial” (OLIVEIRA In. ATLÂNTICO, n¹, 1942, p. 170). Esta fala demonstra que, acima de um simples espaço de comunicação cultural, a Atlântico detinha princípios estabelecidos pelos dois órgãos regentes.

Neste sentido, a ideia da Política de Espírito criada por António Ferro despontava não sozinha, mas em conjunto com a ideia do “Lago Lusitano” expressado por Oswaldo

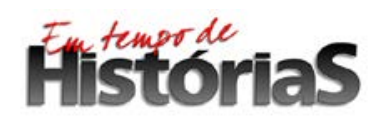


Aranha ${ }^{9}$. Com isto em mente, a Atlântico passava a ser uma peça da política de aproximação luso-brasileira como referido nas notas da primeira edição da revista quando Oliveira expressou que:

(...) só agora, com o Presidente Getúlio Vargas e com o Doutor Oliveira Salazar como Chefe do Govérno, essa política, tem o seu sistema e se realiza, efetivamente, com continuidade, como política das duas Nações. Agora sim, a 《Unidade Espiritual» é um programa de Govérno. E é essa a única política da revista Atlântico (IBIDEM, p.170).

A Unidade Espiritual em que Oliveira citou, oriunda da fala de Lourival Fontes, expõe que havia neste momento uma construção de aproximação entre os dois países com os laços históricos, culturais e políticos. Neste ponto o próprio Vargas em fala na inauguração do Instituto de Alta Cultura Luso-Brasileiro asseverou que:

Não nos prende, neste momento, nenhum elo de subordinação ou de vassalagem, quer de ordem económica, quer de ordem intelectual, quer de ordem política ou de qualquer outra espécie. É, apenas, a aproximação espontânea, pelo vínculo da fraternidade que nos uniu no passado e que projecta as duas nações para o futuro, entrelaçadas no ideal de um progresso comum (IBIDEM, p.2)

Através das falas de Fontes, Oliveira e Vargas podemos perceber, portanto, que os três indicam duas situações em comum: a primeira refere-se a ideia de uma unidade transnacional pautada na ideia de uma “espiritualidade” ou de passado em comum. Neste sentido o fortalecimento dos laços culturais luso-brasileiros ampliava a importância dos dois países no cenário internacional.

O segundo ponto notado nas falas refere-se à aproximação dos países. Através dos enxertos expostos é perceptível que eles perpassavam pela ideia de uma aproximação política calcada nos projetos comuns das duas nações, nos ideais entrelaçados ou na ideia de um progresso conjunto. E por este motivo estes projetos resultam efetivamente em uma atitude política de aproximação. E aqui a palavra Política deve ser destacada, pois, ela refere-se não apenas a vontade de um grupo de intelectuais, mas de efetivas realizações e ações conjuntas que levavam os dois países a dialogarem e concretizarem medidas reais.

Por este ponto, a revista Atlântico foi um espaço para a efetivação do discurso de aproximação, como um lugar de diálogo conjunto para o fortalecimento e continuidade desta ação política. Com isto em mente, diversos escritos atestaram a importância desta ação, como no caso da edição três da revista em que o secretário José Osório de Oliveira

\footnotetext{
${ }^{9}$ Aranha, ao expor a existência de um "Lago Lusitano”, aponta o Oceano Atlântico como um espaço em comum de Portugal e do Brasil, e que este seria o traço de união dos povos de língua portuguesa.
} 
aponta que “está mais presente do que nunca no Brasil, em resultado, sem dúvida, do Acôrdo Cultural e de toda a «Política de Espírito» que, no capítulo das relações lusobrasileiras, os dois Governos e os seus organismos de Propaganda têm desenvolvido ultimamente" (OLIVEIRA In. ATLÂNTICO, n³3, 1943, p.201).

Através do Acordo Cultural ações binacionais passaram a existir como forma de interação e tentativa de uma comunhão luso-brasileira. A Atlântico, para isso, teve papel chave através da divulgação das ações como nos casos da publicação de livros brasileiros em Portugal, da produção de coleções de livros de autores brasileiros intituladas Cruzeiro do Sul e Atlántico e também da Convenção Luso-Brasileira sôbre a Língua Portuguesa de 29 de dezembro de 1943.

Além das divulgações a respeito de publicações e convenções, outras ações que mereceram serem destacadas pela Atlântico foram as conferências transnacionais promovidas pela Seção Brasileira do SPN com a presença de diversos participantes da revista.

Para além das obras públicas e privadas de interação culturais, a Atlântico serviu também com o propósito de fortalecer o discurso da união dos dois povos. Um exemplo referente a isso pode ser visto no discurso racial presente dentro da revista.

Neste ponto, o discurso de Getúlio Vargas em sua posse na Academia Brasileira de Letras, e que foi publicado na revista, aponta o cerne da unidade racial explorado pelos participantes da Atlântico. Vargas em sua fala assevera que “a língua era e ainda é o único instrumento de expressão entre os dois povos e o laço mais forte de consangüinidade capaz de manter o contacto íntimo e fraternal brasileiros e portugueses” (VARGAS In: ATLÂNTICO, n5, 1944).

Sua fala aponta chaves fundamentais no entendimento da ideia da raça lusitana: consanguinidade e fraternalidade. A ideia de Portugal pai e Brasil filho circulou pela Atlântico e fortaleceu o imaginário de seus participantes como forma de uma união acima da diplomática ou material, mas sagrada.

Um exemplo deste viés pode ser visto na fala de Augusto de Castro intitulada Juventude e Esplendor do Brasil no qual, relacionado à questão da miscigenação e da inserção dos negros e outros povos na sociedade brasileira ele aponta que

(...) êste facto de maturidade política e de adaptação histórica (...) estão longe de ser estranhos ao impulso e a tradição que a civilização portuguesa, forte de uma experiência colonial (...) imprimiu e levou ao alvorecer da história e à própria génese da civilização brasileira. (...)

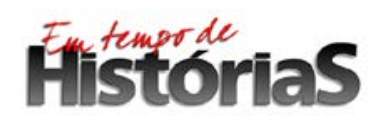

(PPGHIS/UnB) No. 33, Brasília, Ago - Dez 2018 ISSN 2316-1191 
Através dela que perdura e durará uma das expressões da influência subjectiva e da hereditariedade política da nossa raça a raça nova que nos continua no continente americano (CASTRO In. ATLÂNTICO, $\mathrm{n}^{\circ} 2$, 1942, p.195).

O discurso de raça do Brasil circunda, portanto, em uma gênese familiar, e por este motivo os dois transformam-se em uma só raça.

Outro exemplo a respeito da ideia da raça como fortalecimento dos laços de fraternidade dos dois povos pode ser visto no poema de Paulo Silveira de nome Baía na qual ele escreve que “(...) e foi da audácia genital; da brava gente lusitana; que violou a terra americana; fecundando o solo brasileiro (...)” (SILVEIRA In. ATLÂNTICO, n², 1942, p.266). Novamente a ideia de uma união consagrada pela consanguinidade fortalece o discurso da Unidade Espiritual exposta por Fontes, em um sentido de apontar que, acima da materialidade, Portugal e Brasil são unidos pelo sangue, pela cultura e pela religião.

O discurso orientado para a Atlântico, portanto, servia para a aproximação dos dois países mesmo com a ausência de reciprocidade econômica. A aliança luso-brasileira pautava-se, por este motivo, na proximidade cultural dando razão, por isso, para as escolhas políticas. Como povos similares, com características próprias, suas instituições políticas tinham seu propósito de ser. E neste sentido o discurso de aproximação lusobrasileira se apoiava para legitimar as áreas políticas e sociais.

O fim do regime Vargas em 1945, no entanto, foi não somente um marco para as mudanças políticas no Brasil como também da Política do Atlântico. Nas notas da sexta edição da primeira fase da Atlântico José Osório de Oliveira aponta o fim da primeira fase da Atlântico expondo que “Atlântico, numa nova fase, passará a ser mais frequente e acessível, para melhor realizar sua missão. O nosso propósito não foi fazer um álbum, mas uma antologia” (OLIVEIRA In. ATLÂNTICO, n6, 1945, p.199).

Ainda que a Atlântico tenha permanecido com seu propósito, sua segunda fase passou por turbulências. A ausência dos investimentos da DIP, recém encerrada em maio de 1945, assim como a inconsistência de António Ferro em sua posição como diretor do Secretariado Nacional de Informação em Portugal enfraqueceram os aportes da aproximação luso-brasileira, e também da revista. Acima disso, o contexto de 1945 que marcava o fim do Estado Novo, a redemocratização no Brasil e uma nova ordem internacional no pós-Segunda Guerra Mundial, acabaram por enfraquecer a aproximação luso-brasileira, concluindo, assim, o sentido da Política do Atlântico.

\section{Hitstorias}




\section{Conclusão}

Originada do Acôrdo Cultural Luso-Brasileiro de 4 de setembro de 1941, a Revista Atlântico: Luso-Brasileira foi um espaço de comunicação e aproximação brasileira e portuguesa. A sua publicação durante os anos de 1942 a 1945 apoia um período de intensa relação de Portugal com o Brasil, na qual os dois países buscaram através de uma rede de intelectuais e promoções artísticas e culturais aproximar as elites e os discursos identitários.

Sua produção demonstra os cuidados e intenções dos dois departamentos de propaganda dos regimes Estado-Novistas, que fizeram da Atlântico um ponto central de ações de produção de discursos que pudessem ser associadas as obras governamentais e atitudes políticas.

Por este motivo a Atlântico fez parte de uma ação política que buscava aproximar discursos do Brasil e de Portugal para fortalecer as instituições luso-brasileiras. Neste viés, religião e práticas culturais passaram a receber atenção como forma de promoverem as unidades nacionais dos dois países. A Política do Atlântico pode ser pensada, portanto, como uma tentativa dos regimes de Getúlio Vargas e Oliveira Salazar de se utilizarem mutuamente para promoverem e legitimarem suas instituições e seus regimes políticos.

Ainda que esta aliança tenha surtido poucos efeitos concretos de forma imediata conforme Amado Cervo (2000) e Paula Santos (2010) apontam, principalmente por causa da ênfase de aproximação do governo de Vargas com os Estados Unidos da América, suas consequências podem ser vistas até os dias de hoje nos discursos de fraternidade luso-brasileira e lusofonia. Ainda que a Política do Atlântico como forma de aproximação institucionalizada tenha se encerrado com o fim do regime varguista, as construções e ações efetivadas pelos seus idealizadores e seguidores prosseguem circulando pelos mares do Atlântico Sul.

\section{REFERÊNCIAS BIBLIOGRÁFICAS}

ALMEIDA, Antônio C. S. A Formação Político-Cultural do Brasil: Excertos do Pensamento de Sergio Buarque de Holanda e Gilberto Freyre. Revista Ponto-e-Vírgula, São Paulo, v.9, $1^{\circ}$ sem. 2011.

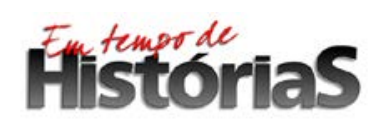


CERVO, A; MAGAlhãES, J. C. d. Depois das Caravelas: As Relações Entre Portugal e Brasil 18082000. Brasília: Editora Universidade de Brasília, 2000.

FAUSTO, B. História do Brasil. São Paulo: Editora da Universidade de São Paulo: Fundação do Desenvolvimento da Educação, 1995.

GOMES, A. de C. Autoritarismo e corporativismo no Brasil: intelectuais e construção do mito Vargas. In. MARTINHO, Francisco C.P.; PINTO, António. O corporativismo em Português: Estado, Política e Sociedade no Salazarismo e no Varguismo. Rio de Janeiro: Civilização Brasileira, 2007. p. 79-108.

GONÇALVES, M. Afinidades Republicanas na Era do Anticlericalismo: Brasil, Portugal e a "questão jesuítica” de novembro de 1910. Cadernos de História. Belo Horizonte, v.15, n.23, 2 sem. p. 63-87. 2014. PECÁUT, Daniel. Os Intelectuais e a Política no Brasil: entre povo e a nação. São Paulo: Editora Ática, 1990.

PINTO, A. C. O Estado Novo Português e a vaga autoritária dos anos 1930 do século XX. In. MARTINHO, Francisco C.P.; PINTO, António. O corporativismo em Português: Estado, Política e Sociedade no Salazarismo e no Varguismo. Rio de Janeiro: Civilização Brasileira, 2007.

SANTOS, G. "Política do Espírito": O bom gosto obrigatório para embelezar a realidade. Media e Jornalismo, [S.I.], n¹2, ano 7, p. 59-72, 2008.

SANTOS, J. de C. Literatura colonial portuguesa: espaço, poder e imperialismo. In: Revista Fórum identidades. Ano 3, Vol. 5, jan.-jun. 2009, p.47.

SANTOS, P. M. dos. AMORIN, P. As relações Portugal-Brasil na primeira metade do século XX (19101945). In: SOUZA, F. SANTOS, P. AMORIN, P. As relações Portugal -Brasil no século XX. Porto: CEPESE, 2010.

SERPA, Élio C.. Revista Brasília: "Ver o outro nos próprios olhos". Revista do Instituto Histórico e Geográfico Brasileiro, Rio de Janeiro, v. 171, n448, p. 99-128, jan/dez .2010.

SILVA, Alex G. da. Cultura Luso-Brasileira em Perspectiva: Portugal, Brasil e o Projeto da Revista Atlântico (1941-1945). 2011227 f. Dissertação (Mestrado) - Curso de Mestrado em História Social, Faculdade de Filosofia, Letras, Ciências Humanas, Universidade de São Paulo, São Paulo, 2011. TORGAL, Luís Reis. Literatura oficial no Estado Novo: prêmios literários do SPN/SNI. In. Revista de História das Idéias. Vol. 20, 1999.

SECRETARIADO DE PROPAGANDA NACIONAL. Acôrdo Cultural Luso-Brasileiro. Rio de Janeiro, 1941

SOUZA, R. José Osório de Oliveira e suas reflexões sobre a “moderna” literatura brasileira. Revista Desassossego, v. 7, n. 13, p. 100-108, 26 ago. 2015.

Atlântico: Revista Luso-Brasileira, n 1, 2, 3, 4, 5, 6, Lisboa, SPN/DIP, Maio de 1942 a Abril de 1945 (Primeira Série).

\section{Filistororias}

